MATEC Web of Conferences 44, 02079 (2016)

DOI: $10.1051 /$ matecconf/20164402079

(C) Owned by the authors, published by EDP Sciences, 2016

\title{
The Research of Detection and Treatment of Tunnel Lining Cavity
}

\author{
Mei Ling Guo ${ }^{1}$, Shui Ping Huang ${ }^{2, a}$ \\ ${ }^{1}$ Continuing Education College, Guangdong University of Science and Technology, 523083, Dongguan, China \\ ${ }^{2}$ International Education College, Guangdong University of Science and Technology, 523083, Dongguan, China
}

\begin{abstract}
It was a threat that the lining cavity had a many risk of the tunnel operation, thus detection and prevention was particularly important. The general causes of tunnel lining cavity and corresponding prevention measures will be summarized, and methods which includes detect lining cavity and processing data were given. Last, a real engineering was given for illustrating the practical method of tunnel lining cavity detection process. The proposed method has a great significance to ensure the safety of the tunnel operation.
\end{abstract}

\section{Introduction}

Different kinds of tunnels in China have damages of varying degrees, ranging from the hazard of water leaking, the crack of tunnel lining, the void of tunnel lining, the problem of frost, the danger of earthquake, to the pollution of inner air, and the risk of fire, among which the void of the tunnel lining causes more subtle damage to the tunnel.

Table 1. Causes and solutions of the void of tunnel lining [1,2].

\begin{tabular}{|c|c|}
\hline Causes & Solutions \\
\hline $\begin{array}{c}\text { Void caused by concrete } \\
\text { shrinkage. }\end{array}$ & $\begin{array}{c}\text { Improve the flow of concrete } \\
\text { by adding the water reducer or } \\
\text { reducing the water-cement } \\
\text { ratio. }\end{array}$ \\
\hline $\begin{array}{c}\text { Void caused by } \\
\text { insufficient pressure of } \\
\text { the pumping or } \\
\text { inadequate flow of the } \\
\text { concrete. }\end{array}$ & $\begin{array}{c}\text { Ensure sufficient pumping } \\
\text { pressure before construction. }\end{array}$ \\
\hline $\begin{array}{c}\text { Void caused by } \\
\text { inappropriate place or } \\
\text { wrong choice of the } \\
\text { pumping. }\end{array}$ & $\begin{array}{c}\text { Use skew pumping mouth, if } \\
\text { there is slope, a high pumping } \\
\text { mouth is needed for the } \\
\text { pouring. }\end{array}$ \\
\hline $\begin{array}{c}\text { Void caused by } \\
\text { inadequate loose paving } \\
\text { of the waterproofing } \\
\text { layer }\end{array}$ & $\begin{array}{c}\text { i) The flatness of the primary } \\
\text { support should be checked, and } \\
\text { the unqualified one should be } \\
\text { leveled. } \\
\text { ii) Ensure adequate coefficient } \\
\text { of loose paving material. }\end{array}$ \\
\hline $\begin{array}{c}\text { Void caused by } \\
\text { improper sealing }\end{array}$ & \begin{tabular}{c} 
Adopt the valve for the sealing. \\
\hline
\end{tabular} \\
\hline
\end{tabular}

Such problems are seen as follows: Falling rocks caused by the collapse of the void lead to bend, squeeze and destroy the tunnel, which causes the primary support damage; the joint action of the structure-rock system based on the mechanism of mechanics cannot be formed, making the force undependable and the surrounding rock unsteady; it also leaves space for water storage, adverse to waterproof and drainage, and may cause the pressure of frost heaving. Here are some causes of the void of the tunnel lining (Table 1).

It is necessary to inspect whether there is such void of the tunnel lining and accordingly deal with it appropriately, in order to ensure the safety of the tunnel work. Two specifications are consulted to direct the inspection: The Technology of Testing the Tunnel Engineering and Nondestructive Testing Procedures of the Quality of the Railway Tunnel Lining.

Now, it is to discuss the testing principles of the void of the tunnel lining, and to give a specific project case on the inspection and post-construction of the tunnel lining, which renders certain reference value to similar cases.

\section{Inspection of the tunnel lining void}

\subsection{Testing principle [3-5]}

Geological radar is usually applied for the inspection of the void of the tunnel lining. Based on the principle of the propagation characteristics of electromagnetic waves in lossy media, the transmitting antenna transmits highfrequency electromagnetic pulses to the measured media, when encountering uneven body (or interface), it will reflect part of the electromagnetic waves, the reflection coefficient of which mainly depends on the dielectric constant of the measured media. By timely receiving and processing the reflected waves of this part, the radar host achieves the purpose of inspecting and identifying the target object.

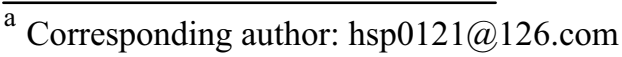


Table 2. Testing principle.

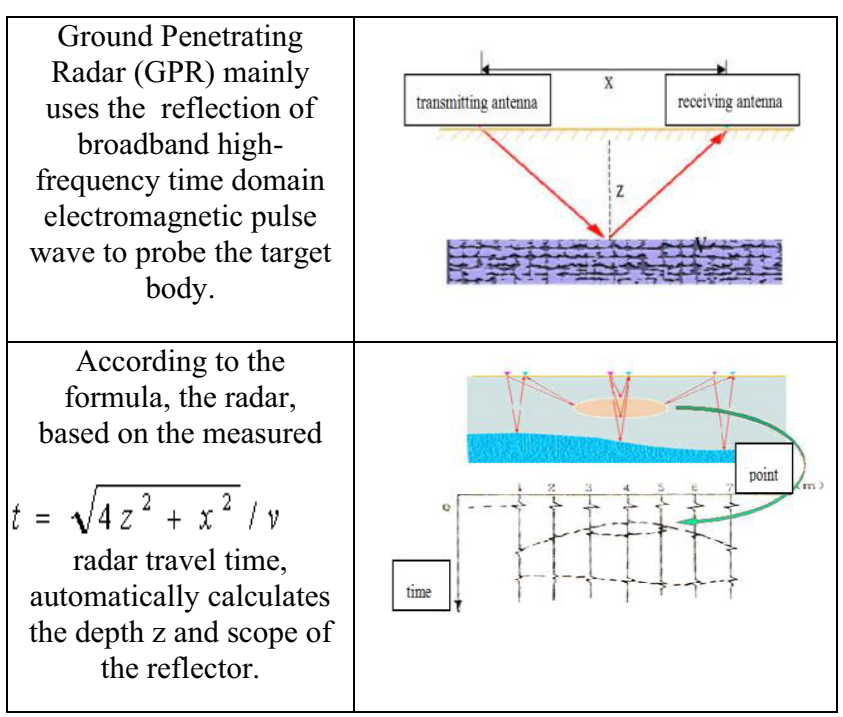

Radar antenna transmits electromagnetic waves to the concrete. As concrete, steel, hole and the density of concrete are different, their dielectric constant differentiate from each other, which makes electromagnetic waves reflecting at the interface of different media possible, received by the receiving antenna on the surface of the concrete. According to the time difference of electromagnetic wave transmitter and the reflected wave and the propagation speed of electromagnetic waves in the concrete, the reflector's distance from the surface is determined to detect the steel, the defect location and depth within the concrete.

According to the principle above, radar can be used to detect the location of the steel in the concrete, the thickness of the protective layer and the location, depth and scope of void, porosity and other defects. Table 2 shows the working principle of radar and its detection methods. $500 \mathrm{MB}$ antenna, which can reach out to the depth of 3 to 4 meters, is commonly used for GPR to detect the void of the tunnel lining. [6-10].

\subsection{Testing procedure}

Table 3. Testing procedure.

\begin{tabular}{|c|c|}
\hline \multirow{2}{*}{$\begin{array}{l}\text { Preparation } \\
\text { phase }\end{array}$} & $\begin{array}{l}\text { Learn designing information of the tunnel, } \\
\text { determine detection scheme, and collect data of } \\
\text { surrounding rock. }\end{array}$ \\
\hline & $\begin{array}{l}\text { Tell the construction team to conduct the traffic } \\
\text { in the tunnel and clean the on-site facilities to } \\
\text { ensure a smooth and safe testing work. }\end{array}$ \\
\hline \multirow{5}{*}{$\begin{array}{l}\text { Implement- } \\
\text { ation phase }\end{array}$} & Check the equipment \\
\hline & $\begin{array}{l}\text { Lay out the measuring point. Generally the on- } \\
\text { site measuring line is longitudinal-centered, } \\
\text { with survey line } 3,5 \text { and } 7 \text {, and circumferential- } \\
\text { auxiliary, based on point measurement. }\end{array}$ \\
\hline & $\begin{array}{l}\text { Detect radar and calibrate medium parameter. } \\
\text { i) Knowing the thickness of certain } \\
\text { part or material, measure the precast object } \\
\text { similar to the tunnel; } \\
\text { ii) Use dual antenna to measure where no car is } \\
\text { available in the tunnel; } \\
\text { iii) Drill holes to measure. }\end{array}$ \\
\hline & Analyze images and process datum. \\
\hline & Write the testing report. \\
\hline
\end{tabular}

\section{Project case study}

\subsection{General introduction}

Guowan Tunnel lies in DK276+937.5 from the beginning to the end, the total length of which is 135 meters, with the V-level surrounding rock. The entrance of the tunnel is of chamfered type, while the exit adopts single pressure type. The grass slope protection of concrete skeleton is adopted on the entrance slope, while the anchor frame beam protection is adopted on the exit slope. DK276+870-DK276+895 is of chamfered type, DK276+895-DK276+920 uses I type composite lining, DK276+920-DK276+990 uses II type composite lining, and open-cut construction is available for DK276+990DK277+005. The entrance and the exit chooses 30m, $35 \mathrm{~m}$ respectively of $\varphi 108$ large steel pipe as advance support, with the middle section using $\varphi 42$ small steel pipe as fore poling.

\subsection{Detection of the implementation situation}

Field testing is conducted in accordance with the requirements of the construction side and the regulations. Radar survey lines are set longitudinally for the detection on the left arch lumbar, vault, the right arch lumbar in each of the tunnel as far as possible.

In actual field testing, as the site constraint of some tunnel construction sites and out of safety considerations of equipment and person, datum are not collected from some positions unqualified for testing conditions.

The data of GPR reflects the electrical distribution of subsurface medium, and transforms it into geological distribution. Such information as geology, construction, and GPR must be combined to get an overall picture of the target object. Lack of density and void appear in the tunnel lining. Air in the void of surrounding rock or concrete distinctively differentiates in permittivity from mold-built concrete, shotcrete, and surrounding rock. Therefore on the time profile, the same phase radar wave fractures, bents upward, and draws a clear boundary within void, concrete, and surrounding rock. If steel or steel grille exists during the process, its impact should be taken into consideration.

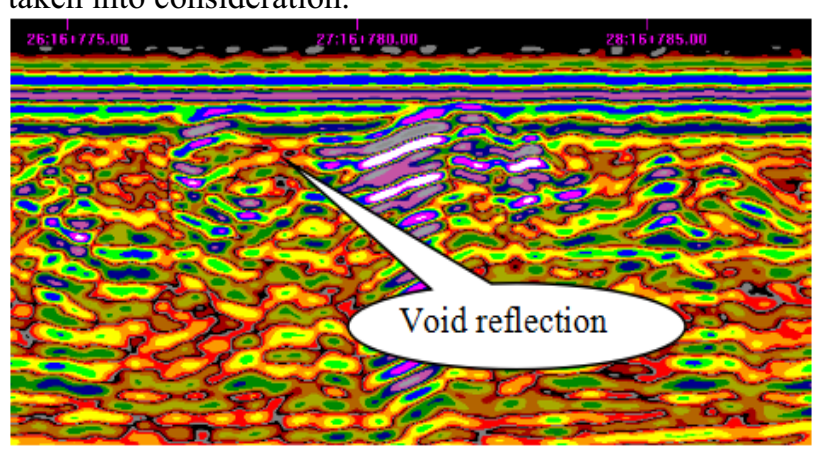

Figure 1. Profile of the radar reflection of the void.

Figure 1. is the depth profile deriving from the processed original data, and testing result (Table 4) is achieved after being analyzed. The void is characterized by strong reflection signal in the lining interface, and obvious vibration phase, at which lower interface there is 
still strong reflection signal. These two sets of signal differentiate largely in time interval.

Table 4. Testing results.

\begin{tabular}{|c|c|c|c|}
\hline \multirow{5}{*}{ Name } & Position & Mileage & $\begin{array}{c}\text { Depth } \\
\text { (cm) }\end{array}$ \\
\hline \multirow{5}{*}{$\begin{array}{c}\text { Guowan } \\
\text { Tunnel }\end{array}$} & \multirow{3}{*}{ vault } & DK276+909-DK276+913 & $24-51$ \\
\cline { 3 - 4 } & & DK276+947-DK276+952 & $26-52$ \\
\cline { 3 - 4 } & & DK276+925-DK276+929 & $33-60$ \\
\cline { 3 - 4 } & & DK276+967-DK276+970 & $28-50$ \\
\cline { 3 - 4 } & $\begin{array}{c}\text { right } \\
\text { arch } \\
\text { lumbar }\end{array}$ & DK276+982-DK276+985 & $29-57$ \\
\hline
\end{tabular}

\subsection{Treatment program}

Table 5. Requirements on backfill material.

\begin{tabular}{|c|c|}
\hline No. & Content \\
\hline 1 & Be of self-stability and space -filling \\
\hline 2 & $\begin{array}{c}\text { Backfill material is liable to deform, and can be } \\
\text { filled into void. }\end{array}$ \\
\hline 3 & segregating from water and diluting with it \\
\hline 4 & $\begin{array}{c}\text { Be of small proportion and taking little load on the } \\
\text { lining. }\end{array}$ \\
\hline
\end{tabular}

Table 6. Designing of the treatment program.

\begin{tabular}{|c|c|}
\hline $\begin{array}{l}\text { Treatment } \\
\text { program }\end{array}$ & Content \\
\hline \multirow{3}{*}{$\begin{array}{c}\text { Designing } \\
\text { parameter } \\
\text { of the } \\
\text { lining } \\
\text { drilling }\end{array}$} & Drill hole diameter: $3 \mathrm{~cm}$ \\
\hline & $\begin{array}{l}\text { Vent setting: } 30 \mathrm{~cm}-50 \mathrm{~cm} \text { above the drilling } \\
\text { hole }\end{array}$ \\
\hline & Inclination angle: $3^{\circ}$ downward \\
\hline \multirow[b]{3}{*}{$\begin{array}{l}\text { Designing } \\
\text { parameter } \\
\text { of the } \\
\text { grouting }\end{array}$} & Either is $\mathrm{OK}$. \\
\hline & $\begin{array}{l}\text { Water-cement ratio to single pipe of cement } \\
\text { grouting is } 0.5: 1 \text { to } 1: 1 \text {, and } 42.5 \mathrm{R} \text { early } \\
\text { strength portland cement is available }\end{array}$ \\
\hline & $\begin{array}{l}\text { Blend in proportion superplasticizer, } \\
\text { accelerating agents and other additives } \\
\text { through test; the additive quality should } \\
\text { conforms to regulation GB } 8076 \text {. Effect } \\
\text { should be tested before usage, initial setting } \\
\text { time should be controlled within 5min, and } \\
\text { final setting time within } 10 \mathrm{~min}\end{array}$ \\
\hline \multirow{2}{*}{$\begin{array}{l}\text { Setting of } \\
\text { the } \\
\text { grouting } \\
\text { pressure } \\
\text { and grout } \\
\text { tube }\end{array}$} & $\begin{array}{l}\text { Initial pressure of grouting pressure is } 0.2- \\
0.5 \mathrm{MPa} \text {, while final pressure is } 0.5-1.2 \mathrm{MPa} \text {. } \\
\text { Either the method of gradual pressurized } \\
\text { grouting or constant pressurized grouting can } \\
\text { be adopted. Install the grouting core tube on } \\
\text { the embedded grout pipe. Control the } \\
\text { grouting speed within } 30-60 \mathrm{~L} / \mathrm{min} \text {. }\end{array}$ \\
\hline & $\begin{array}{l}\text { Avoid the damage of waterproof board of the } \\
\text { embedded grout pipe. Put anti-blocking } \\
\text { facility on the top end of the grout pipe, and } \\
\text { seal the hole firmly after grouting. }\end{array}$ \\
\hline
\end{tabular}

During the construction:

i) According to the mileage showed in the testing report, confirm and locate the position of the void. ii) Accurately drill holes with rock drill in the lining void, and install grout pipe in the two ends of the void so that it can be fixed in the lining. The space around the grout pipe can be filled with the anchoring agent, and a valve should be set to avoid a secondary grouting.

iii) Clean the pipe hole before grouting and reasonable order should be taken when grouting.

iv) If the pressure rises rapidly but the slurry is hard to be injected or infused a little, the water-cement ratio should be increased, and the slurry concentration be lowered. In the meanwhile, check whether the grouting pipe is blocked, when it does, clear it.

v) Whether to stop grouting depends on the grouting pressure, grouting time, and grouting volume. One should often check the slurry quality, control the water-cement ratio, the grouting pressure, and the grouting volume of the slurry and fill in the grouting record pipe by pipe during the process

\subsection{Treatment effect}

After the construction process, drill hole for coring in the grouting area when the slurry solidifies to get a better effect.

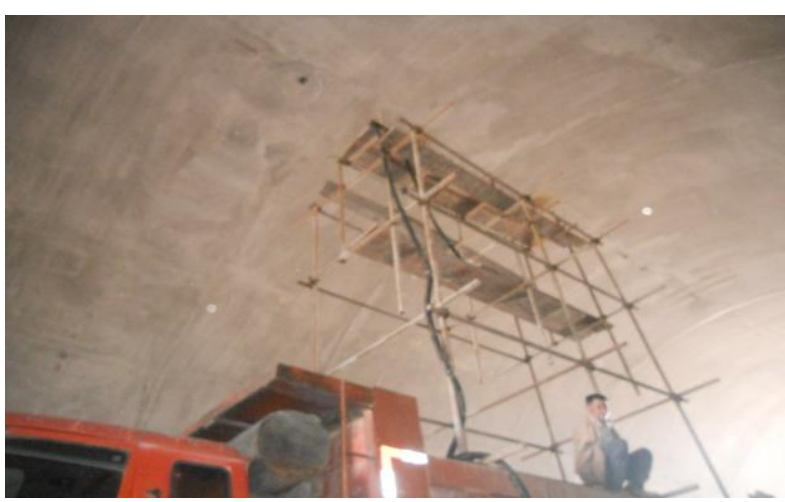

Figure 2. The grouting process of the lining void.

\section{Conclusion}

i) Causes of the tunnel lining void includes as follows, void caused by concrete shrinkage, insufficient pressure of the pumping or inadequate flow of the concrete, inappropriate place or wrong choice of the pumping, inadequate loose paving of the waterproofing layer. Corresponding solutions are: improve the flow of concrete by adding the water reducer or reducing the water-cement ratio, ensure sufficient pumping pressure before construction, use skew pumping mouth, and if there is slope, a high pumping mouth is needed for the pouring, the flatness of the primary support should be checked, and the unqualified one should be leveled, ensure adequate coefficient of loose paving material, and adopt the valve for the sealing.

ii) Geological radar is usually applied for the tunnel inspection. This paper summaries the testing principle and data processing method of the geological radar. 
iii) This paper, taking Guowan Tunnel as an example, tells in details testing methods of the tunnel lining void and the treatment program on on-site construction.

iv) What covers in this paper renders great value to the inspection and treatment of the tunnel lining void, which in turn ensures the tunnel safety.

\section{References}

1. Ministry of Railways of the People's Republic of China, Acceptance Criteria on the Quality of Railway Tunnel Construction, Beijing: China Railway Publishing House, 2003.

2. Liu Yong-hua, Numerical Simulation of Secondary Lining Void or Crack in Vault. Highway Tunnel, (3), pp.11-13, 2006.

3. Peng Yue, Wang Gui-lin, Zhang Yongxing. Study on Impact of Lining Void on Safety of the In-service Tunnel Structure. Underground Space and Engineering Journal, 4(6), pp.1101-1104, 2008.
4. Zhang Zheng-guo. Application of GPR New Technology in the NDT of Tunnel Defect. Chengdu University Journal, (4), pp.6-10, 2003.

5. Liu Hai-jing, Zheng Jia-yan, Luo Xin, Liu Yuanming. Classification of Tunnel Defect and Parameter Quantitative Research Method. Modern Tunnelling Technology, (suppl), pp.619-623, 2006.

6. Fu Wei, Zhou Hong-feng, Fan Jin-jia. Analysis and Prevention of Concrete Crack of Tunnel secondary lining. Communications Standardization, (7), pp.53$55,2005$.

7. Zhou Tao, Dang Hai-yan, Wang Guo-xin. Analysis and Treatment of Collapse Caused by Tunnel Lining Void. Shanghai Geology, (2), pp.11-12, 2007.

8. Ding Xiao-xin, Su Hui. Management of Construction Contract, Beijing: Chemical Industry Press, 2005.

9. Liu Chang-ming, Song Hui-lian. Management of Project Bidding, Beijing: Peking University Press, 2006. 